\title{
Sensibilidade e resistência de amostras de Salmonella Typhimurium isoladas de súnos abatidos no Rio Grande do Sul/Brasil frente aos desinfetantes químicos quaternário de amônio e iodofor
}

\author{
Sensitivity and resistance of samples of Salmonella Typhimurium isolated in slaughter swines in the \\ state Rio Grande do Sul/Brazil, front to disinfectants quaternary ammonium and iodophor.
}

\author{
Luciane Martins Borowsky ${ }^{1}$ Marjo Cadó Bessa ${ }^{2}$ Marisa de Itapema Cardoso ${ }^{3}$ \\ César Augusto Marchionatti Avancini ${ }^{4}$
}

\section{RESUMO}

Na prevenção da ocorrência ou na interrupção da evolução de enfermidades infecto-transmissíveis comuns aos animais e aos seres humanos, como é o caso da salmonelose, o uso de um desinfetante capaz de agir sobre o agente causal quando em vida livre, no ambiente, exerce grande importância. No entanto, a resistência microbiana, intrínseca ou adquirida, pode apresentar-se como um limitante no uso deste instrumento sanitário. Objetivando monitorar a sensibilidade da Salmonella Typhimurium, 96 amostras isoladas de suínos abatidos no Estado do Rio Grande do Sul,Brasil, foram confrontadas com dois compostos químicos desinfetantes (origem comercial) de uso freqüente em ambientes de produção animal e de transformação de seus subprodutos: um quaternário de amônio e o iodofor. Foram usadas as concentrações indicadas pelo fabricante e uma menor para simular possível situação de sub-concentração. O método de verificação foi o de diluição através do teste de suspensão, observando a inativação bacteriana nos tempos de contato 5 , 15, 30 e 60 minutos. Como resultados obtidos, todas as amostras foram inativadas quando utilizado o composto quaternário de amônio, em ambas as concentrações. Frente ao iodofor, 4 (quatro) amostras mostraram-se resistentes a este composto na concentração indicada e 59 frente à subconcentração. Conclui-se ser necessário, seja para a eleição ou para o monitoramento da eficácia, o confronto dos desinfetantes/anti-sépticos com bactérias presentes nos ambientes específicos de produção animal ou mesmo nos de transformação de seus subprodutos.

Palavras-chave: Salmonella Typhimurium, quaternário de amônio, iodofor, desinfetante, Medicina Veterinária Preventiva, sanidade animal, suinocultura.

\begin{abstract}
For prevention of infectious diseases common to man and animals such as salmonellosis, the successful use of disinfectants is of great importance. However, intrinsic or acquired resistance presented by microorganism against these compounds may constitute a limiting aspect in disinfections protocols. This study was aimed at monitoring the sensitivity of 96 Salmonella Typhimurium strains isolated from slaughter pigs in the state of Rio Grande do Sul, Brazil. The isolates were tested against quaternary ammonium and iodophor, which represent two commercial disinfectants commonly used in animal production. The tested disinfectants were used in the concentration recommended by the fabricant and in a subconcentration in order to simulate a possible field situation. Dilution suspension tests were conducted, observing the inactivation of each S.Typhimurium isolate after 5, 15, 30 and 60 minutes of contact with each compound. All tested isolates were inactivated by the quaternary ammonium compound in both concentrations. Four isolates revealed resistant to iodophor in the recommended concentration and 59 isolates when a sub-concentration was tested. The testing of resistance against disinfectants in microorganisms present on farm and in food processing plants might be an important step on monitoring the effectiveness of adopted disinfections protocols.
\end{abstract}

Key words: Salmonella Typhimurium, quaternary ammonium, iodophor, preventive Veterinary Medicine, animal health, swine breeding.

\section{INTRODUÇÃO}

As bactérias do gênero Salmonella têm ampla distribuição mundial, são correntes nos

${ }^{1}$ Programa de Pós-graduação de Microbiologia Agrícola e do Ambiente, Universidade Federal do Rio Grande do Sul (UFRGS), Porto Alegre, RS, Brasil.

${ }^{2}$ Pós-graduação em Ciências Veterinárias, UFRGS, Porto Alegre, RS, Brasil.

'Departamento de Medicina Veterinária Preventiva, Faculdade de Veterinária, UFRGS, Porto Alegre, RS, Brasil.

${ }^{4}$ Departamento de Medicina Veterinária Preventiva, Faculdade de Veterinária, UFRGS, Porto Alegre, RS, Brasil, Av. Bento Gonçalves 9.090, 91540000, Porto Alegre, RS, Brasil. E-mail: cesar.avancini@ufrgs.br. Autor para correspondência. 
ambientes de produção animal, constituindo-se também em potencial problema sanitário para a saúde pública. Alguns sorovares de Salmonella são adaptados a espécie de hospedeiro específico, como o Typhi para humanos, o Choleraesuis para suínos e o Dublin para bovinos (SCHWARTZ, 2000), enquanto outros como o Typhimurium, o Anatum e o Newport, entre outros, afetam um grande número de hospedeiros, desempenhando importante papel na disseminação da infecção entre as diferentes espécies (HIRSH, 1990). A transmissão de Salmonella sp. ao homem ocorre principalmente pela ingestão de produtos de origem animal contaminados, o que pode resultar em toxinfecções alimentares, sendo considerada uma das mais importantes causas de doença de origem alimentar entre humanos (EKPERIGIN \& NAGARAJA, 1998).

Nas toxinfecções alimentares registradas, tanto no Brasil quanto no exterior, os sorovares de Salmonella isolados com maior freqüência têm sido o Enteritidis e o Typhimurium(ESPER et al., 1998; JAKABI et al., 1999; VAN DER WOLF et al., 2001). Entre as principais medidas de prevenção ou de controle aplicáveis em programa sanitário para esta enfermidade, encontram-se a limpeza e a desinfecção (FEDORKAGRAY et al., 1994; BORCH et al,1996; BLAHA, 1996).

GUERREIRO et al. (1984) conceituam a desinfecção ( superfícies inanimadas) e a anti-sepsia (superfícies de tecidos vivos) como o controle ou a eliminação dirigida de microrganismos considerados indesejáveis em situações-problema específicas, pela atuação em sua estrutura ou em seu metabolismo, independente de seu estado funcional, visando a prejudicar a transmissão desses microrganismos e/ou reduzir a sua dose infectante. Diversos compostos químicos ativos desinfetantes estão disponíveis no mercado, sendo os mais utilizados, na suinocultura, os compostos de amônia quaternária, glutaraldeído, iodóforo e hipoclorito (KICH et al., 2004).

O Código Zoosanitário Internacional, ao tratar sobre o tema medidas de higiene e segurança sanitária na produção animal, alerta sobre a existência de poucos desinfetantes universais, bem como indica a necessidade de haver controle sobre a atividade biocida dos produtos existentes. Variáveis como a amostra do microrganismo de interesse e a concentração do produto recomendada pelo fabricante devem ser submetidas a avaliação para comprovar sua eficácia (DOMINGUES \& LANGONI, 2001). Observações pessoais indicam ser igualmente importante fator de interferência na eficácia dos desinfetantes as subdoses, ou subconcentrações de uso, conseqüência, freqüentemente, do procedimento de desinfecção ser delegado a pessoas sem destreza de manipulação, sem qualificação ou conhecimento sobre as técnicas de diluição.

Nos últimos anos, consideráveis avanços têm sido realizados no entendimento da resposta de diferentes microrganismos aos agentes antimicrobianos. A resistência pode ser uma característica própria do microrganismo (intrínseca) ou adquirida por mutação, mediada por plasmídios ou transposons. A resistência intrínseca tem sido demonstrada por bactérias Gram negativas, esporuladas, micobactérias e, sob certas circunstâncias, estafilococos. A resistência adquirida ou mediada por plasmídios tem sido associada aos compostos mercuriais e a outros sais metálicos. Mais recentemente, resistência adquirida a certos tipos de biocidas (desinfetantes) tem sido observada notadamente pelos estafilococos (McDONNELL \& RUSSEL, 1999).

CHAPMANN (1998) alerta que a experiência com resistência a antibióticos e a biocidas indicam que não há agente químico antimicrobiano que não possa, eventualmente, induzir resistência nos microrganismos. E que essa observação, acoplada com a do decréscimo da taxa de oferecimento de novos grupos químicos biocidas ativos, aumentam a necessidade de saber manejar o risco do desenvolvimento de resistências, bem como responder rapidamente a sua eventual ocorrência.

A resistência a antimicrobianos antibióticos tem sido exaustivamente estudada. No entanto, a resistência bacteriana frente a produtos desinfetantes, mesmo sendo uma preocupação crescente, é pouco compreendida (RUSSEL, 1998; McDONNELL \& RUSSEL, 1999). Nesse sentido, destaca-se a quase inexistência de investigação científica que avalie continuadamente a eficácia antimicrobiana de desinfetantes utilizados em saúde e produção animal. Estas, quando existentes, na maior parte das vezes, são resultado de estudos confrontando os produtos com amostras-padrão internacionais.

Os compostos quaternário de amônio, entre os quais encontra-se o cloreto de benzalcônio, são detergentes catiônicos sintéticos que possuem atividade antimicrobiana. Possuem boa estabilidade, solubilidade em água e toxicidade relativamente baixa (PELCZAR et al., 1980). A ação bactericida é atribuída à inativação de enzimas responsáveis pelos processos de transformação de energia, à, desnaturação de proteínas celulares e à ruptura da membrana celular (ROMÃO, 1996).

Os iodóforos são compostos formados por agente químico antimicrobiano iodo com agentes tenso-ativos, que funcionam, ao mesmo tempo, como carreadores e solventes desse elemento. Apresentam 
as características bactericidas rápidas e irreversíveis do iodo, tendo como vantagens gerais adicionais não mancharem as superfícies e não serem irritantes de mucosa (PELCZAR et al., 1980). O exato mecanismo através do qual o iodo age como microbicida não está esclarecido, mas assume-se como sendo principalmente provocado pela alteração na síntese protéica devido à oxidação do grupo S-H da cisteína (GOTTARDI, 1991).

Medidas de higiene ambiental são indispensáveis para programas de sanitários de biossegurança frente à Salmonella sp. Uma vez que o uso de antimicrobiano/biocida de ambiente é procedimento crítico em um protocolo de controle de Salmonella, visando a orientar sua escolha em relação a esse agente causal, em suinocultura, este estudo teve como objetivo avaliar a sensibilidade e/ou resistência de 96 (noventa e seis) amostras de Salmonella Typhimirium isoladas de suínos abatidos no Rio Grande do Sul/Brasil frente a dois compostos químicos desinfetantes, um quaternário de amônio e o iodofor.

\section{MATERIAL E MÉTODOS}

\section{Amostras bacterianas}

As 96 amostras de Salmonella Typhimurium utilizadas no presente estudo estão armazenadas no Laboratório de Medicina Veterinária Preventiva, Faculdade de Veterinária, Universidade Federal do Rio Grande do Sul (UFRGS). As amostras foram isoladas, no período de 1999 à 2001, de fezes, linfonodos mesentéricos, linfonodos submandibulares, tonsilas e embutidos de suínos abatidos em matadouros/ frigoríficos no Rio Grande do Sul, Brasil. Quanto à origem das amostras, 48 delas foram isoladas de animais diferentes. As demais 48 foram isoladas de 24 animais, duas de cada um, em dois locais diferentes em cada animal. Considerou-se as amostras dos mesmos animais como sendo diferentes entre si porque, na avaliação de sensibilidade e resistência a antibióticos, as isoladas pareadas em 13 animais apresentaram perfil antimicrobiano antibiótico e/ou fagotipos diferentes. As 22 amostras restantes foram inseridas no trabalho com a possibilidade de diferenciarem-se quanto ao perfil antimicrobiano desinfetante.

As amostras são mantidas congeladas (-200C) em caldo de infusão cérebro e coração (BHI - Merck $^{\circledR}$ ) e glicerol. Para a reativação bacteriana, pequena quantia foi retirada por meio de alça bacteriológica, semeada em Ágar Tripsona Soja $\left(\right.$ Merck $\left.^{\circledR}\right)$ e incubada a $37^{\circ} \mathrm{C}$ por 24 horas. Para os testes, uma colônia era retirada da placa semeada e colocada em $5 \mathrm{~mL}$ de caldo BHI, incubado por 18-24 horas, tornado-se a “cultura-mãe”.
Desinfetantes

O composto quaternário de amônia foi obtido de um produto comercial contendo a seguinte composição: 15g cloreto de benzalcônio e veículo $100 \mathrm{~mL}$. A concentração recomendada é de $0,6 \mathrm{mg} \mathrm{L}^{-1}$, tendo sido adotada como subconcentração de uso $0,3 \mathrm{mg} \mathrm{L}^{-1}$. Já o desinfetante iodofor foi obtido de uma composição comercial contendo: 2,5g de iodo; 2,75g de ácido fosfórico e veículo $100 \mathrm{~mL}$. A concentração recomendada é de $0,1 \mathrm{mg} \mathrm{L}^{-1}$, tendo sido adotada como subconcentração de uso $0,05 \mathrm{mg} \mathrm{L}^{-1}$. A diluição dos compostos químicos foi feita em água destilada estéril.

\section{Teste de eficácia de desinfetante}

O método foi o de diluição, com teste de suspensão, descrito pelo Ministério da Agricultura e Abastecimento (BRASIL, 1993). Tubos de ensaio contendo $10 \mathrm{~mL}$ do desinfetante, com a concentração recomendada e a subconcentração, receberam $0,1 \mathrm{~mL}$ da “cultura-mãe” (que continha aproximadamente 1,4 x 109UFC mL ${ }^{-1}$ ). Por meio de alça bacteriológica, após os tempos de contato 5, 15, 30 e 60 minutos, uma alíquota era retirada e colocada em tubos de ensaio contendo $1 \mathrm{~mL}$ do meio de cultura BHI. Esses tubos eram agitados, incubados a $37^{\circ} \mathrm{C}$ e as observações feitas nos tempos 24, 48, 72 e 96 horas. A leitura destes tubos indicava os resultados: não-turvação, considerado bactéria inativa; turvação, considerado bactéria ativa.

\section{RESULTADOS E DISCUSSÃO}

Como pode ser observado na tabela 1 , quando confrontadas com o desinfetante quaternário de amônio, nas duas concentrações usadas, as 96 (100\%) amostras de Salmonella foram sensíveis e inativadas. Quando confrontadas com o iodofor, na concentração recomendada, foram inativadas 95,8\% das amostras, e, em subconcentração, 38,5\% delas. Na tabela 2, podem ser observados os resultados da confrontação das amostras com os desinfetantes, levando em consideração os tempos de contato. Comparado ao quaternário de amônio, 100\% das amostras foram inativadas nas duas concentrações usadas, já nos 5 minutos de contato.

Confrontadas pelo composto iodofor, na concentração recomendada, foi necessário tempo de contato de 60 minutos para inativar 95,8\% das amostras. Setenta e oito amostras $(81,2 \%)$ foram inativadas já aos 5 minutos de contato. Onze amostras $(11,4 \%)$ foram inativadas aos 15 minutos de contato, 3 amostras (3,1\%) aos 30 minutos de contato. Quatro $(4,2 \%)$ amostras foram resistentes durante todos os tempos observados. 
Tabela 1 - Número de amostras de Salmonella Typhimurium sensíveis (inativadas) frente aos grupos químicos desinfetantes quaternário de amônia e iodofor, em duas concentrações de uso - Universidade Federal do Rio Grande do Sul, 2005.

\begin{tabular}{llcc}
\hline \multicolumn{3}{c}{ Concentração } \\
\hline \multirow{4}{*}{$\begin{array}{llcc}\text { Ação } \\
\text { Quaternário de }\end{array}$} & $\begin{array}{l}\text { inativação } \\
\text { amônio }\end{array}$ & 96 & 96 \\
& sem & - & - \\
inativação & & \\
& & & 37 \\
Iodofor & $\begin{array}{l}\text { inativação } \\
\text { sem }\end{array}$ & 92 & 59 \\
& inativação & 4 & \\
\hline
\end{tabular}

Quando o desinfetante iodofor foi utilizado como subconcentração, em relação à recomendada pelo fabricante, mesmo com 60 minutos de tempo de contato, 59 (61,4\%) amostras foram resistentes. Quanto á sensibilidade, aos 5 minutos de contato, 27 amostras (28,1\%) foram inativadas. Aos 15 minutos, 7 (sete) amostras (7,3\%) em, aos 30 minutos, 3 (3,1\%), estavam inativas.

Das 22 amostras pareadas isoladas de 11 animais e ainda não diferenciadas, apenas quatro não apresentaram diferença de comportamento quanto a alguma variável testada (grupo químico, concentração e tempo de contato). Essa observação evidencia a possibilidade que o perfil antimicrobiano desinfetante seja um instrumento para diferenciar amostras bacterianas.

Estudo semelhante de verificação da sensibilidade e resistência a antimicrobianos foi realizado por CARDOSO (2000), investigando a eficiência de desinfetantes frente a 80 amostras de Salmonella Entiritidis isoladas de carcaças de frangos

Tabela 2 - Número de amostras de Salmonella Typhimurium sensíveis (inativadas), por tempo de contato, frente à duas concentrações dos grupos químicos desinfetantes quaternário de amônia e iodofor Universidade Federal do Rio Grande do Sul, 2005.

\begin{tabular}{lcccc}
\hline \multicolumn{2}{c}{ Quaternário de amônio } & \multicolumn{2}{c}{ iodofor } \\
\hline tempo contato & CR & SC & CR & SC \\
5 & 96 & 96 & 78 & 27 \\
15 & - & - & 11 & 7 \\
30 & - & - & 3 & 3 \\
60 & - & - & - & - \\
resistentes & - & - & 4 & 59 \\
\hline
\end{tabular}

$\mathrm{CR}=$ concentração recomendada; $\mathrm{SC}=$ subconcentração. no Estado do Rio Grande do Sul. Usando também a técnica de suspensão, diferente do presente experimento porque realizado na presença de matéria orgânica e tempo de contato de até 20 minutos, os resultados obtidos com os compostos químicos comerciais iodofor e quaternário de amônia foram parcialmente divergentes dos que agora encontrou-se para as amostras de Salmonella Typhimurium. Frente ao iodofor, com 20 minutos de contato, quatro das 80 amostras de Salmonella Entiritidis foram resistentes. Já frente ao quaternário de amônia, no mesmo tempo de contato, 73 delas foram resistentes.

Deve-se estar alerta para possíveis equívocos em conclusões obtidas pela comparação entre observações e experimentos, quando estas pesquisas usam, por exemplo, métodos, técnicas e testes, microrganismos ou procedimentos diferentes aos usados nesta pesquisa. Por outro lado, essas comparações, buscando similaridades ou antagonismos, podem ser bons instrumentos para melhor interpretar resultados.

Em investigação realizada por SANDER et al. (2002), 17 amostras bacterianas dos gêneros Staphylococcus, Enterococcus, Salmonella, Pseudomonas, Proteus, Escherichia e Pasteurella, isoladas em ambiente de avicultura, foram confrontadas com três grupos de desinfetantes: compostos fenólicos, quaternário de amônia e peróxido de hidrogênio. No caso da Salmonella sp., os desinfetantes do grupo dos fenóis inibiu a maioria das amostras, enquanto o grupo do quaternário de amônia foi incapaz de promover a inativação das mesmas amostras, o que difere do resultado encontrado neste estudo, no qual o desinfetante com base quaternário de amônia mostrou ser ativo.

KICH et al. (2004) avaliaram, em duas etapas experimentais, com teste de micropipetagem em placa, a atividade antibacteriana de seis desinfetantes comerciais frente a amostras de Salmonella Typhimurium também isoladas de suínos. Há dificuldade de comparação dos resultados, posto que foi considerada sensível a amostra que apresentou redução de quatro logaritmos em relação às unidades formadoras de colônia iniciais. De qualquer maneira, pode-se perceber semelhança parcial com os resultados obtidos na investigação que apresentamos. Esses autores observaram na primeira etapa experimental, frente a uma única amostra de Salmonella Typhimurium e tempo de contato de 15 minutos, que ela foi sensível ao composto amônia quaternária e iodóforo. No entanto, diferentemente dos resultados obtidos no presente estudo, os autores citados indicam terem observado resistência de todas as 11 amostras 
confrontadas com a amônia quaternária e o iodóforo em um único tempo de contato de 5 minutos.

Em trabalho realizado por WILLINGHAN et al. (1996), bactérias isoladas de incubadoras de ovos (câmaras de eclosão) tiveram sua resistência testada frente a preparações comerciais desinfetantes de quaternário de amônia, fenol e glutaraldeído. As bactérias foram expostas ao desinfetante nas diluições recomendadas pelos fabricantes, por tempos de contato de 5, 10 e 15 minutos. Aproximadamente $8 \%$ das isoladas de duas das três incubadoras foram resistentes às concentrações recomendadas pelos fabricantes e, em alguns casos, até acima das concentrações e do tempo de exposição. Semelhantemente a nossa investigação, quando usado o desinfetante com composto químico ativo quaternário de amônia, não houve indicação de resistência do gênero Samonella.

\section{CONCLUSÕES}

Observou-se que as 96 amostras de Salmonella Typhimurium testadas apresentaram diferente sensibilidade (inativação bacteriana), tendo esta variado com o grupo químico desinfetante confrontado, com o tempo de contato e com a concentração usada.Todas as amostras de Salmonella Typhimurium foram sensíveis ao produto comercial tendo como composto químico ativo o quaternário de amônia (cloreto de benzalcônio), independentemente do tempo de contato ou da concentração, seja na recomendada pelo fabricante seja na subconcentração de uso. Frente ao produto comercial cujo composto químico ativo é o iodofor, quatro amostras apresentaram resistência frente à concentração recomendada pelo fabricante, mesmo com tempo de contato de 60 minutos, e 59 foram resistentes na subconcentração de uso.

Os resultados obtidos nesta pesquisa enfatizam a orientação de que para a eleição do grupo químico desinfetante quaternário de amônia (cloreto de benzalcônico) ou do iodofor, frente ao microrganismo Salmonella Typhimurium deve-se levar em conta o monitoramento da sensibilidade/resistência de amostras isoladas para cada ambiente de saúde, de produção animal ou mesmo para os ambientes de beneficiamento de seus subprodutos.

\section{REFERÊNCIAS}

BLAHA, T. The impact of Salmonella on the swine industry. In: SWINE CONFERENCE, 1996, Nebrasca. Proceedings... Nebrasca: School University of the Nebrasca, 1996. p.1-20.

BORCH, E.et al. Hazard identification in swine slaughter with respect to food borne bacteria. International Journal of Food Microbiology, v.30, p.9-25, 1996.

BRASIL, Portaria no 101, de 17 de agosto de 1993. Ministério da Agricultura, Pecuária e Abastecimento. Métodos de Análise Microbiológica para Alimentos. Diário Oficial [Da República Federativa do Brasil], Brasília, v.n.p. 11937-11945, 17 de agosto de 1993, Seção I, 1993.

CHAPMANN, J.S. Characterizing bacterial resistence to preservatives and disinfectants. International Biodeterioration \& Biodegradation, v.41, p.241-245, 1998.

CARDOSO, M.O. Avaliação da sensibilidade a antimicrobianos e eficiência de desinfetantes em amostras de Salmonella enteritidis isoladas de carcaças de frangos no estado do Rio Grande do Sul. 2000. $108 \mathrm{f}$. Dissertação (Mestrado em Ciências Veterinárias) - Curso de Pós-graduação em Ciências Veterinárias, Universidade Federal do Rio Grande do Sul.

DOMINGUEZ, P.F.; LANGONI, H. Manejo sanitário animal. Rio de Janeiro: EPUB, 2001. p.210.

EKPERIGIN H.E.; NAGARAJA K.V. Salmonella. Microbiology Food Borne Pathoges, v.14, p.17-29, 1998.

ESPER M.R.N.R. et al. Salmonella: sorotipos identificados das cepas isoladas de pacientes hospitalizados e não hospitalizados, na região de Presidente Prudente, SP, no período de 1978-1997. Revista do Instituto Adolfo Lutz, v.57, p.45-50, 1998.

FEDORKA-GRAY, P.I. et al. Transmission of Salmonella Typhimurium to swine. Veterinary Microbiology, v.41, p.333-348, 1994.

GOTTARDI, W. Iodine and iodine compounds. In: BLOCK, S.S. Disinfection, sterilization and preservation. 4.ed. Philadelphia/London: Lea \& Fabiger, 1991. p.152-166.

GUERREIRO, M. et al. Bacteriologia especial: com interesse em saúde pública e saúde animal. Porto Alegre: Sulina, 1984. p.51-66.

HIRSH, D.C. Salmonella. In: BIBERSTEIN, D.V.M.; ZEE, Y.C. Review of veterinary microbiology. Boston: Blackwell Scientific, 1990. p.110-115.

JAKABI, M. et al. Observações laboratoriais sobre surtos alimentares de Salmonella sp., ocorridos na grande São Paulo, no período de 1994 a 1997. Revista do Instituto Adolfo Lutz, v.58, p.47-51, 1999.

KICH, J.D. et al. Evaluation of the antibacterial activity of six commercial disinfectants against Salmonella Typhimurium strains isolated from swine. Acta Scientiae Veterinariae, v.32, n.1, p.33-39, 2004.

McDONNELL, G.; RUSSEL, A.D. Antiseptics and disinfectants: activity, action, and resistance. Clinical Microbiology Reviews, v.12, n.1, p.147-179, 1999.

PELCZAR, M. et al. Microbiologia. São Paulo: McGraw-Hill do Brasil, 1980. Volume I.

Ciência Rural, v.36, n.5, set-out, 2006. 
ROMÃO, C.M.C.A. Desinfecção e esterilização química. In: TEIXEIRA, P.; VALLE, S. (Org). Biossegurança: uma abordagem multidisciplinar. Rio de Janeiro: FIOCRUZ, 1996. p.133-162.

RUSSEL, A.D. Bacterial resistance to disinfectants: present knowledge and future problems. Journal of Hospital Infection, v.43 (suplemnt), p.S57-S68, 1998.

SANDER J.E. et al. Investigation of resistence of bacteria from comercial poultry sources to comercial disinfectants. Avian Disease, v.46, p.997-1000, 2002.
SCHWARTZ, K.J. Salmonellosis. In: STRAW, B.E. et al. Diseases of swine. 8.ed. Ames, Iowa: Iowa State University 2000. Cap.39, p.535-551.

VAN DER WOLF P.J. et al. Salmonella soroprevalence at the population and herd level in pigs in the netherlands. Veterinary Microbiology, v.80, p.171-184, 2001

WILLINGHAN, E.M. et al. Investigation of bacterial resistence to hatchery disinfectants. Avian Disease, v.40, n.3, p.510515, 1996. 